\title{
Comparison of Directional Secular Variation of the Geomagnetic Field between Britain and S. E. Europe
}

\author{
D. H. TARLING ${ }^{1}$ and M. KOVACHEVA ${ }^{2}$ \\ ${ }^{1}$ Department of Geological Sciences, University of Plymouth, PL4 8AA, England \\ ${ }^{2}$ Geophysical Institute, Bulgarian Academy of Science, Sophia 1113, Bulgaria
}

(Received December 23, 1995; Revised September 28, 1996; Accepted January 3, 1997)

\begin{abstract}
Archaeomagnetic data from "Britain" $\left(46^{\circ} \mathrm{N}-58^{\circ} \mathrm{N}, 12^{\circ} \mathrm{W}-8^{\circ} \mathrm{E}\right)$ and S. E. Europe $\left(37^{\circ} \mathrm{N}-49^{\circ} \mathrm{N}\right.$, $15^{\circ} \mathrm{E}-25^{\circ} \mathrm{E}$ ) for the last 2,300 years are selected on the basis of the reported reliability of their archaeological age as well as the precision in the determination of their mean site values. When grouped into mean values for each decade, clear trends are visible for both areas, although individual sites show somewhat anomalous values that are largely attributed to in situ site disturbances. The trend lines, when smoothed by a two-point running mean, appear to give a good representation of the geomagnetic secular variation in these two areas. Comparison between the areas, that are $9^{\circ}$ in latitude and $26^{\circ}$ longitude apart, suggests that an axial geocentric dipole could largely account for the average difference in inclination. The quasi-sinusoidal patterns are more complex in declination than inclination, as previously proposed on less reliable data. There are visual indications of periodicities of some 300 years in inclination and some 400 years in declination but periodicities longer than the time range represented by the data are present. The time of occurrence of maxima and minima for both declination and inclinations suggests that both westward and eastward drift of the geomagnetic field patterns have occurred.
\end{abstract}

\section{Introduction}

Direct measurements of the Earth's magnetic field direction only date from Hartmann (1544). Such data (Malin and Bullard, 1981) show that geomagnetic secular variations have behaviours with characteristic periodicities far longer than the 400 years of available records. Archaeomagnetic and palaeomagnetic data, e.g. Thompson (1982), suggest periods of some 8-12 ka may well be dominant. Confirming such periodicities, over protracted time scales and different regions, is fundamental to constraining geomagnetic field behaviour and, thus, to understanding the origin of the field. Unfortunately, the precision of geological dating is usually far too imprecise for defining secular variation periodicities (but not always, e.g. Turner, 1975; Iorio et al., 1995). Thus the primary data for secular variation studies derive from magnetic studies of limnological and archaeological materials. Lake sediments, in particular, are of major interest as they can provide a nearly continuous record of the changes in the direction of the geomagnetic field at a single location, while most archaeological studies are confined to spot readings of the direction of the field at a particular time and place. Unfortunately, the magnetisation of sediments is influenced by the depositional conditions and particularly post-depositional physico-chemical changes. Consequently, the magnetisations of lake sediments are usually taken to indicate the general, long-term trends in secular variation.

An individual archaeomagnetic direction is generally more reliable than a sedimentary layer for defining a spot reading of the direction of the geomagnetic field at a particular time. However, a secular variation record for any particular locality can only be constructed by correcting similar spot readings from different aged sites and different localities using some model for the unknown regional pattern of the geomagnetic field. As the number and spatial extent of archaeomagnetic observations have increased, the reliability of the spatial correction has become more important. Early archaeomagnetic observations were corrected using the axial geocentric dipole geomagnetic field model (Aitken et al., 1963; Thellier, 1966, 
1981). More recently, following Irving (1964) and Shuey et al. (1970), there has been increasing acceptance of the inclined geocentric geomagnetic field model as the basis for such spatial corrections. Tarling (1989) and Nöel and Batt (1990) found that this model is reasonably valid the present geomagnetic field for areas of some $10^{6} \mathrm{~km}^{2}$, i.e. within some $600 \mathrm{~km}$ of a central location. For such an area, the error in the spatial correction is of the order of the theoretical accuracy of the archaeomagnetic method, $\pm 1^{\circ}$, and smaller than some of the non-Gaussian errors. The latter are mostly a consequence of differential site motion after firing and were estimated, from comparison of sites of reputedly identical age, to be up to some $\pm 5^{\circ}$ (Tarling and Dobson, 1995). Even larger non-Gaussian errors can, of course, arise from errors in the archaeological age assessment but the density of sampling is becoming sufficient for such errors to be identified. Consequently increasingly precise comparisons of the geomagnetic field behaviour can be made between different areas. In this article, archaeomagnetic data from Britain and S. E. Europe are

(a)

British Filtered Data

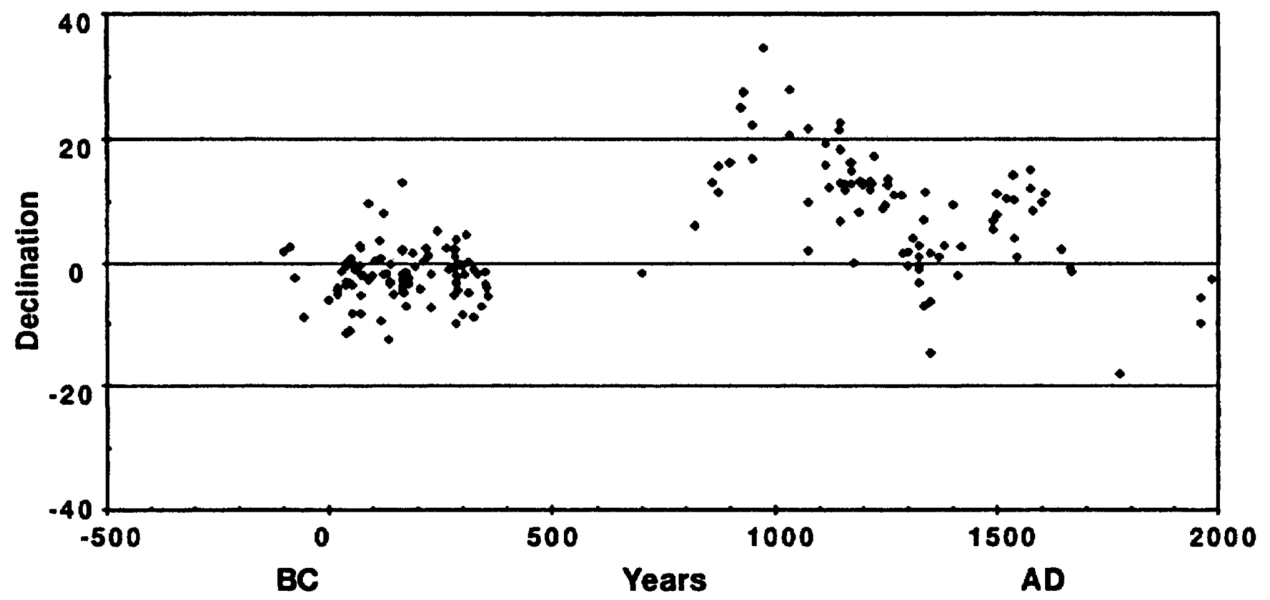

(b)

British Decadal Values

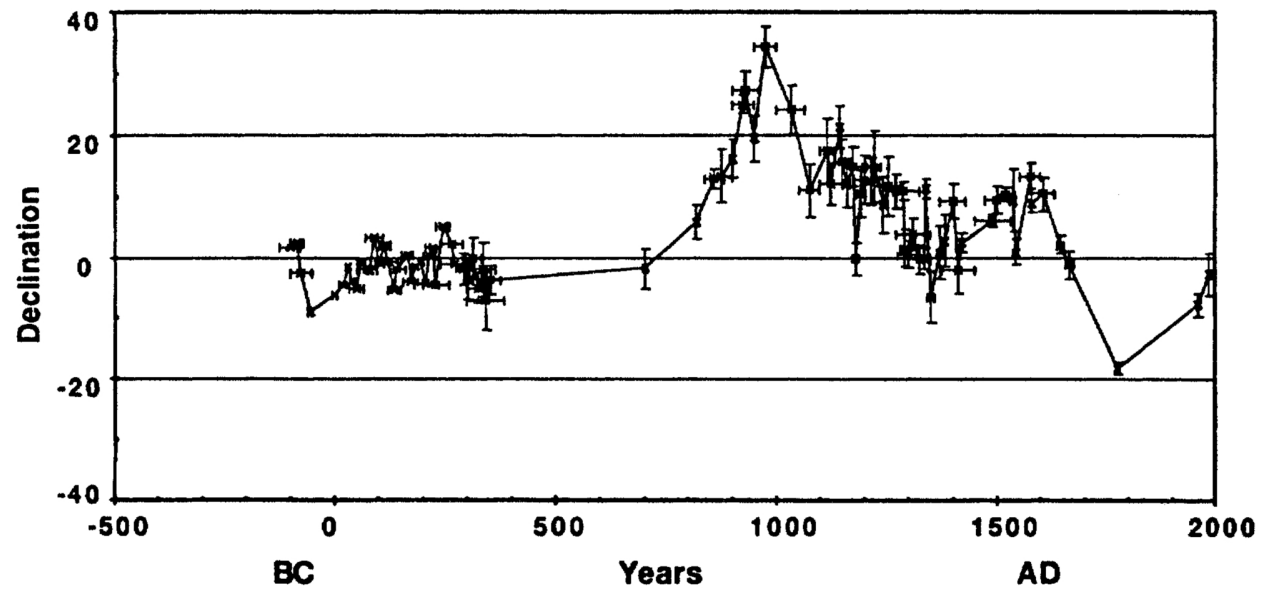

Fig. 1. The British archaeomagnetic filtered decadal declinations and inclinations. The declinations, on the left, are shown (a) without errors bars for the initial filtered data, and (b) with the corresponding age, $\delta$ Declination errors, and trend line on the data grouped into decadal values. Similarly for inclination ((c), (d)), on the right. 
considered and compared. The "British" data incorporate some data from N. W. France while the "South eastern Europe" data set mainly comprises results from the Bulgarian (Kovacheva and Toshkov, 1994; Kovacheva, personal communication) and Hungarian (Marton, 1991, personal communication) regions, but also includes information from Yugoslavia, the Ukraine, northern Greece, and southern Italy (which includes volcanic data (Hoye, 1981; Incoronato, 1996)).

\section{Data Selection and Averaging}

British archaeomagnetic data were originally obtained by Aitken and his colleagues (Aitken, 1970). These were extended by Tarling and his colleagues, particularly A. J. Clark, and more recently by M. Noel and C. M. Batt. The data up to 1987 were reviewed by Clark et al. (1988) and these, with a few new observations, were incorporated into the Plymouth Archaeomagnetic Directional Database (Tarling and Dobson, 1995). (This has been extended to include information from much of Europe, North Africa, the Middle East, Central and Northern America-see Acknowledgements). In the analysis presented here, "British" data were considered to be those deriving from sites bounded by latitudes $58^{\circ} \mathrm{N}$ and $46^{\circ} \mathrm{N}$, and longitudes of $12^{\circ} \mathrm{W}$ and $8^{\circ} \mathrm{E}$; an area of less than $10^{6} \mathrm{~km}^{2}$ and approximately centred on Meriden, the

(c)

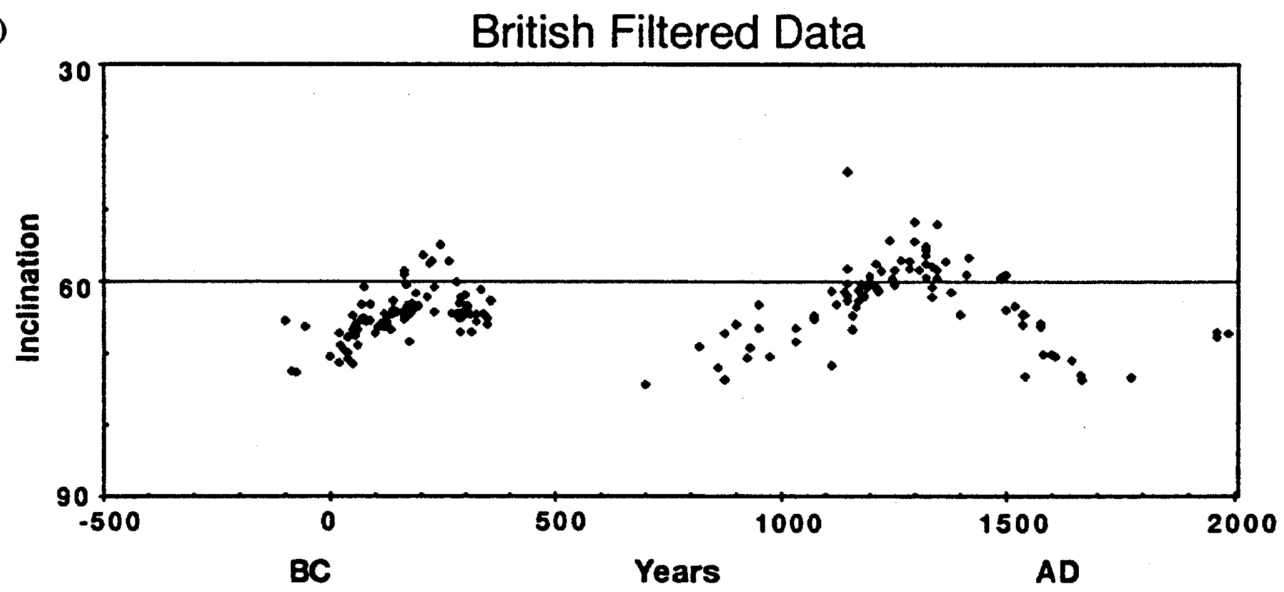

(d)

British Decadal Values

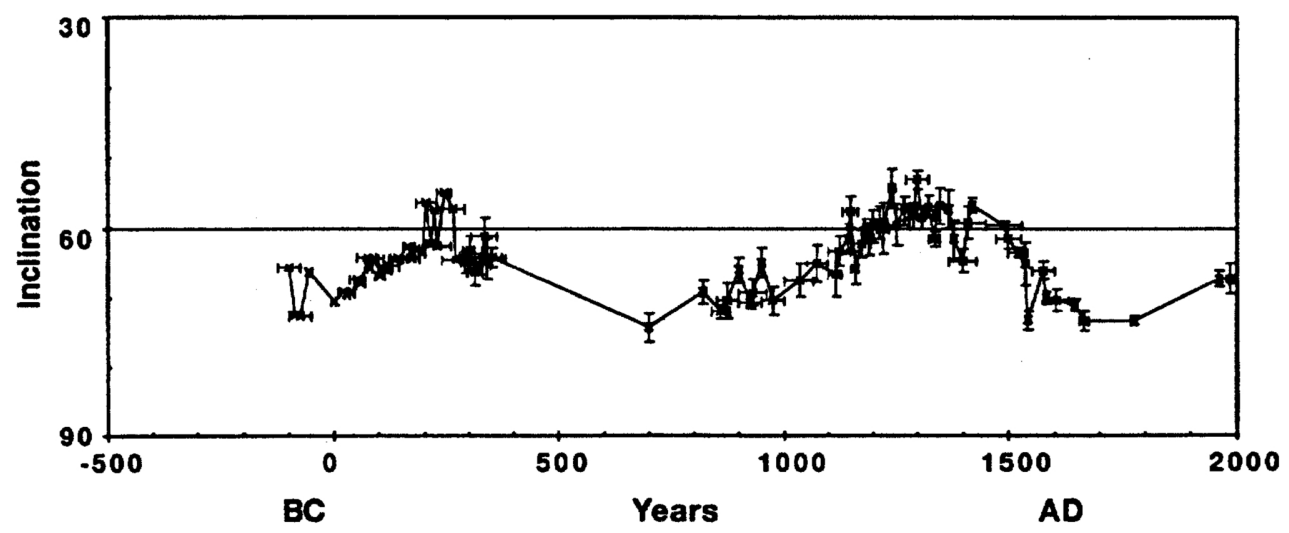

Fig. 1. (continued). 
suggests the presence of a range of periodicities of several centuries or longer duration. However, it is not considered that further harmonic analyses of either data sets would be particularly meaningful at this stage in view of greater knowledge of the magnitude of the unquantified errors in the archaeomagnetic observations (Tarling and Dobson, 1995) which similarly suggest that previous harmonic analyses (Tarling, 1988) must be treated skeptically.

Comparison between the two areas requires correction for the difference in latitude $\left(9.43^{\circ}\right)$ between the two central points. This correction was made using the axial geocentric dipole formula, i.e. $+7.16^{\circ}$ was added to all S. E. European inclination values. The declinations were unchanged. The inclination trends for both areas (Fig. 3(b)) suggest the onset of shallowing in the 6th century AD was almost synchronous, although the steepest inclination appears to have occurred in S. E. Europe in the early 11th century and

(a)

S.E. Europe Filtered Data

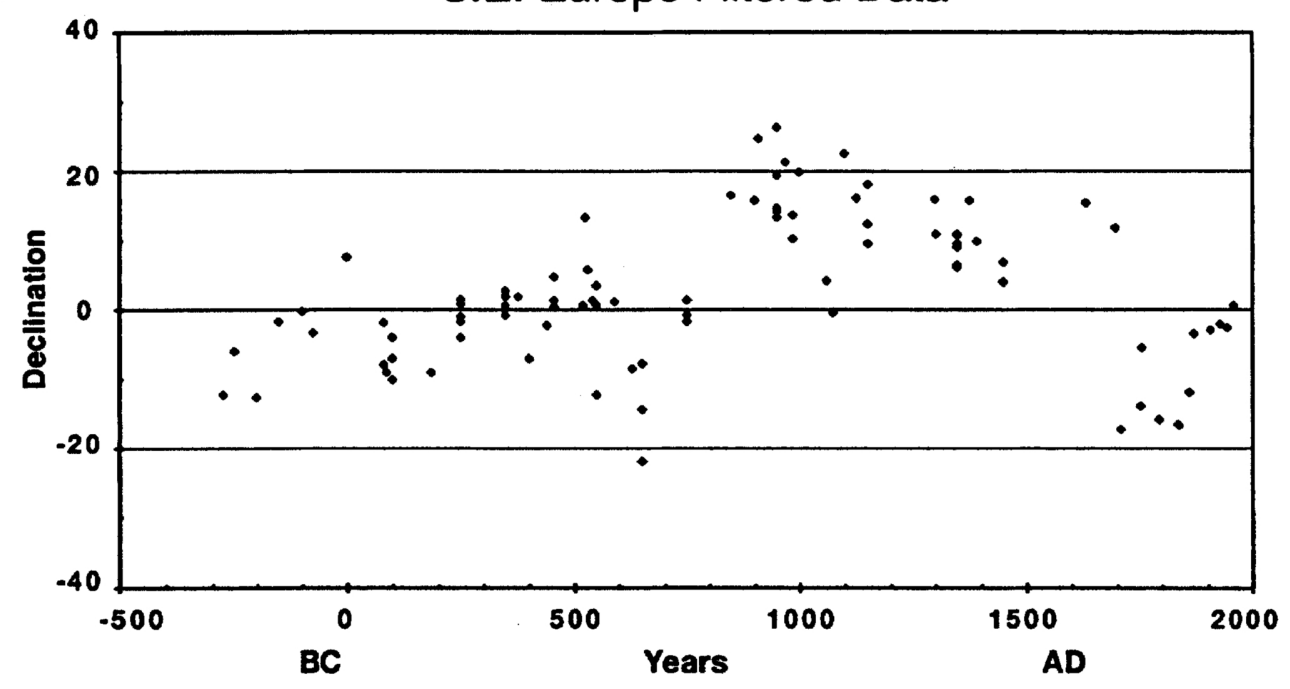

(b)

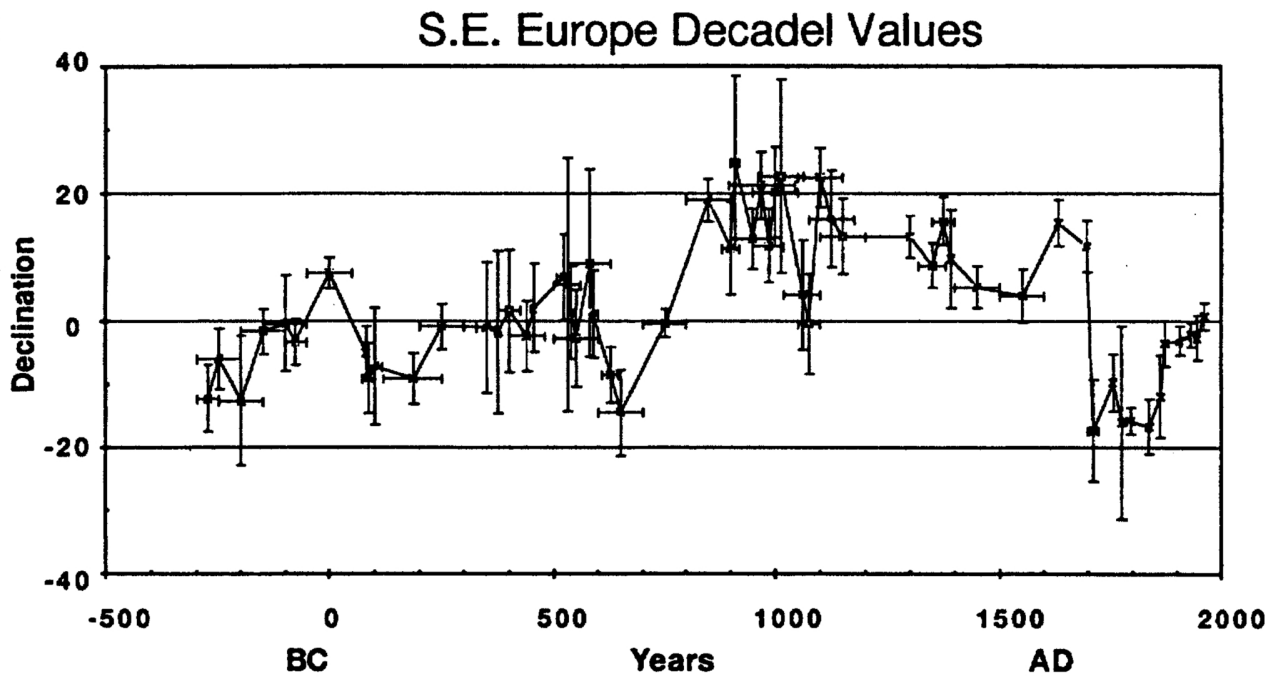

Fig. 2. The S. E. European archaeomagnetic filtered decadal declinations and inclinations. Legend as for Fig. 1. 
geographical centre of England and Wales at $52.43^{\circ} \mathrm{N}, 1.62^{\circ} \mathrm{W}$. Only directions from samples of fired materials that had been subjected to partial demagnetisation were used, although comparisons were made with results from sediments in archaeological contexts (Batt, 1992). The inclined geocentric dipole correction was used to correct the observed site directions to those expected at Meriden.

As these data were being examined for determining geomagnetic secular variations rather than for archaeomagnetic dating purposes, they were filtered to isolate those sites that were both well-dated archaeologically and had a precisely defined mean site vector. Previous filters have been based almost entirely on the reliability of the site mean magnetic vector, as defined by its precision estimate, $k$, and particularly its estimated semi-angle of $95 \%$ Probability, $\alpha_{95}$, as defined by Fisher (1953). Clearly when attempting to construct a long time series of ca. $2 \mathrm{ka}$, the reliability of the archaeological dating of each site is of equal or possibly greater importance. On this basis, 184 sites were selected as having their archaeological age range $\leq \pm 50 \mathrm{yr}$. and their mean site $\alpha_{95} \leq 4^{\circ}$ (Figs. 1(a) and (c)). These were then grouped into decadal values, i.e. all sites for which the mean archaeological age fell within the same decade were averaged, giving equal weight to each site vector in determining the direction of the mean vector.

(c)
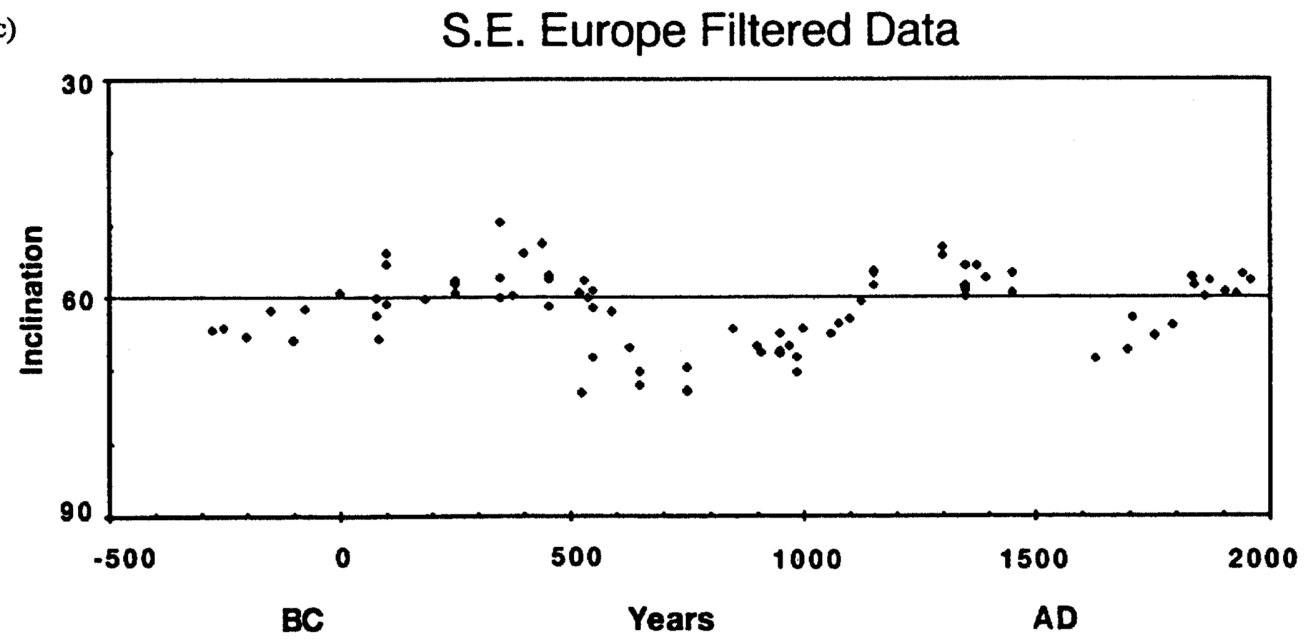

(d) S.E. Europe Decadel Values

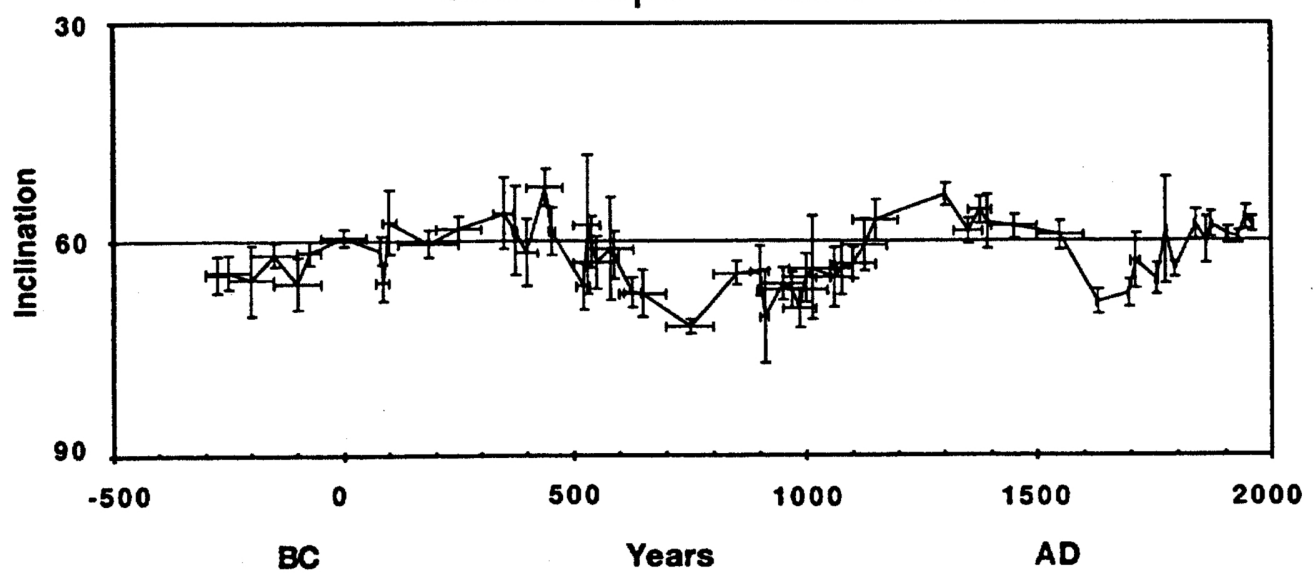

Fig. 2. (continued). 
However, calculating the precision of the mean by the same Fisherian statistics was considered to produce a misleadingly precise value (Tarling and Dobson, 1995) and so the precision of the mean vector, $\alpha_{95}$, was calculated as the arithmetic average of the individual site precisions. The errors in declination and inclination were then derived in the standard way (Tarling, 1983) from the decadal precision value., i.e. the $95 \%$ Probability error in inclination is $\delta$ Incl. $=\alpha_{95}$ and for declination is $\delta$ Decl. $=1.64 \times \alpha_{95}$. This yielded a total of 88 decadal values, 45 of which involved more than one site determination. Provisional secular variation curves were then determined based on the decadal values (Figs. 1(b) and (d)).

Archaeomagnetic studies in Bulgaria, Hungary and Yugoslavia were pioneered by Kovacheva (1969) and Marton (1986). These data were reviewed and compiled at different times and for different regions by Kovacheva (1992), Kovacheva and Toshkov (1994) and Marton (1991). These, with additional data provided by both P. Marton and M. Kovacheva, were incorporated into the Plymouth Archaeomagnetic Directional Database and then examined to determine the optimum central location to which they could be spatially corrected. This was at $43^{\circ} \mathrm{N}, 25^{\circ} \mathrm{E}$. Sites were then selected that were located between latitudes of $37^{\circ} \mathrm{N}$ and $49^{\circ} \mathrm{N}$, and between longitudes $15^{\circ} \mathrm{E}$ and $35^{\circ} \mathrm{E}$, i.e. an area comparable to that for the British data. A total of 129 sites was found, but using selection criteria of sites with an archaeological age range of $\leq \pm 100$ years and a site precision of $\alpha_{95} \leq 5^{\circ}$ reduced this total to 59 sites. These were grouped into decadal values and their site mean errors in declination and inclination determined in the same was as for the British data. (The errors in inclination is therefore $\delta$ Incl. $=\alpha_{95}$, as for the British data, but the error in declination is given by $\delta$ Decl. $=2.1 \times \alpha_{95}$ because of the difference in mean inclination, i.e. latitude, of the two central location points.) The corresponding secular variation curve was then produced (Fig. 2).

\section{The Secular Variation Curves and their Comparison}

\subsection{The British secular variation curves}

The formation of decadal values reduced some irregularities, but the decadal declinations (Fig. 1(a)) still show abrupt changes over time scales of one or two decades. These seem more likely to be attributable to unassessed errors in the archaeomagnetic observations than to geomagnetic field excursions, as discussed by Tarling and Dobson (1995). This does assume that geomagnetic fluctuations were of similar magnitude and form in the past as those today. However, the commonness of site disturbance in the archaeological record suggests that problems in the strict in situ nature of many archaeological sites are far more likely as the cause, particularly as the irregularities are bordered by values that are consistent with relatively smooth geomagnetic variations. On this basis, the longer-term trends, i.e. greater than a few decades, are more safely interpreted as being of geomagnetic origin than individual decadal values, particularly when based on a single site determination. The strong westward declination around 1800 is consistent with direct geomagnetic field observations (Tarling, 1983), as is the swing back to near zero declination in the early 16 th century. There are no independent checks for earlier observations, other than from lake sediments, but the declinations were clearly easterly for most of the 8th to 16th centuries (the single $1412 \mathrm{AD}$ value of $2 \pm 4^{\circ} \mathrm{W}$ being particularly suspect) and there was a consistently almost northerly value during most of the 14th century. The single northerly declination $\left(0 \pm 3^{\circ}\right)$ at $1180 \mathrm{AD}$ is suspect as most decadal values from 1220 to 1075 are between $15 \pm 4^{\circ}$ and $20 \pm 4^{\circ} \mathrm{E}$ and were greater than $20^{\circ} \mathrm{E}$ between 1033 and $925 \mathrm{AD}$. Although the data are sparser, the trend from $930 \mathrm{AD}$ is towards $2 \pm 3^{\circ} \mathrm{W}$ by $700 \mathrm{AD}$. There are few adequately dated observations until immediately post-Roman times, i.e. from the mid 4th century $\mathrm{AD}$. Apart from a small easterly declination in the mid-3rd century $\mathrm{AD}$, the declinations were mostly slightly westerly, possibly with some systematic trends, back to early Roman times, when the declination seems to have been up to $9 \pm 6^{\circ} \mathrm{W}$ in $55 \mathrm{BC}$ and in the earlier part of the 1st century BC, slightly east of North.

The filtered inclination values (Fig. 1(c)) show similar decade irregularities as for declination that are similarly unlikely to be geomagnetic. From the present day, the inclination was steeper in the 16 th and 17 th centuries, consistent with direct geomagnetic measurements. This was preceded by a fairly consistent shallowing back into the mid 14th century (the sharp steepening at $1542 \mathrm{AD}$ is a single site value and hence 
suspect). The inclinations were slightly steeper around 1400 , being reflected in three separate sites, but were shallower back to the 13th century. The earlier trend was steepening back to $700 \mathrm{AD}$, but an absence of reliable data back to immediately post Roman times. The 4th century AD inclination remained fairly constant, with no clear pattern, but may well have been somewhat shallower in 3rd century having earlier been apparently shallowing since the 1 st century $\mathrm{BC}$.

\subsection{The S. E. European secular variation curves}

The present near-northerly declination value was much further west in the 19th and 18 th centuries, with an apparently rapid change from $12 \pm 4^{\circ} \mathrm{E}$ in 1697 to $17 \pm 5^{\circ} \mathrm{W}$ in $1755 \mathrm{AD}$ (Figs. 2(a) and (b)). Prior to this, the declinations were almost all easterly back to $750 \mathrm{AD}$, although very close to North between 1060 and $1075 \mathrm{AD}$. The due North declination $\left(0 \pm 2^{\circ}\right)$ at $750 \mathrm{AD}$ was preceded by a marked westerly declination at $650 \mathrm{AD}$, that had been reached from an easterly declination at $522 \mathrm{AD}$. For earlier times, the declination was further west back to late Roman times, with a brief, almost due North declination between 540 and $550 \mathrm{AD}$. For earlier times, the declination was westerly, except at $1 \mathrm{AD} / \mathrm{BC}$ when it was $7 \pm 3^{\circ} \mathrm{E}$, with a possible trend back to a westerly declination in the 3 rd century $\mathrm{BC}$. The inclination values (Figs. 2(c) and (d)) were increasingly steeper from the present back to $1631 \mathrm{AD}$ with shallowing values back to $1300 \mathrm{AD}$. From $750 \mathrm{AD}$ back to $1300 \mathrm{AD}$, the inclination decreased, with some irregularities, while before that there was a shallowing to $53 \pm 3^{\circ}$ in $440 \mathrm{AD}$. Between the oldest established determination in $275 \mathrm{BC}$, the inclination was gradually becoming steeper, again with possible irregularities that may be archaeomagnetic rather than geomagnetic in origin.

\subsection{Comparisons}

It is clear that, for both regions, there are considerable short term (single site) fluctuations that are almost certainly of archaeomagnetic rather than geomagnetic in origin, although the magnitude of geomagnetic variations may be more realistically represented by archaeomagnetic data than the geomagnetic annual means as these are based on Quiet Day readings alone. Nonetheless, in medium latitudes geomagnetic variations are generally of only a few degrees even during major geomagnetic storms. (In high gradient areas, e.g. high geomagnetic latitudes or close to the Equatorial Jet Stream, such effects may be more serious. It may, ultimately, be possible to investigate the frequency of high latitude events during interesting periods, such as the Maunder Minimum.) At this stage, the data are too sparse to establish the reasons for the departure of some filtered individual site determination from an apparent trend. Consequently some apparent anomalies have been smoothed by calculated the decadal value when more than one determination of is available for that decade (Fig. 3(a)). Further smoothing was then undertaken by assessing the trends of the decadal values by means of a two-point running mean (Fig. 3(b)). Further smoothing, by three-point running means or spline fitting is not thought appropriate as these would excessively reduce the values of the maximum and minimum values.

It is clear, from a simple visual inspection, that there are quasi-sinusoidal variations in both inclination and declination, although the latter is more complex. Such features are well known, having been established in both Europe and Japan many decades ago (Chevallier, 1925; Kato and Nagata, 1949), but are now seen on a vastly greater number of observations. The British inclinations seem to have a wavelength of some 850 year during the last 1,200 years, but the signal is noisy, probably with other wavelengths. Previous analyses of fewer inclination data had shown a $266 \pm 27$ year periodicity (Tarling, 1988). This may still be present but is certainly not visually distinguishable, suggesting that it may have been a harmonic generated by gaps in the data rather than from cyclicities in the actual data. The British declinations have visually less well defined periodicities. This suggests that while the reported (Tarling, 1988) $400 \pm 66$ year periodicity could still be present, the weak $106 \pm 10$ year periodicity is no longer evident. Very similar characteristics are found in the S. E. European data (Fig. 3(b)), with the inclination wavelength being some 850-950 years during the last 1,300 years, and a longer wavelength characterising the earlier period. However, the declination pattern for S. E. Europe is clearer than that for Britain because of the better time coverage of the S. E. European data. Nonetheless, the pattern is still complex and clearly 


\section{Declinations}

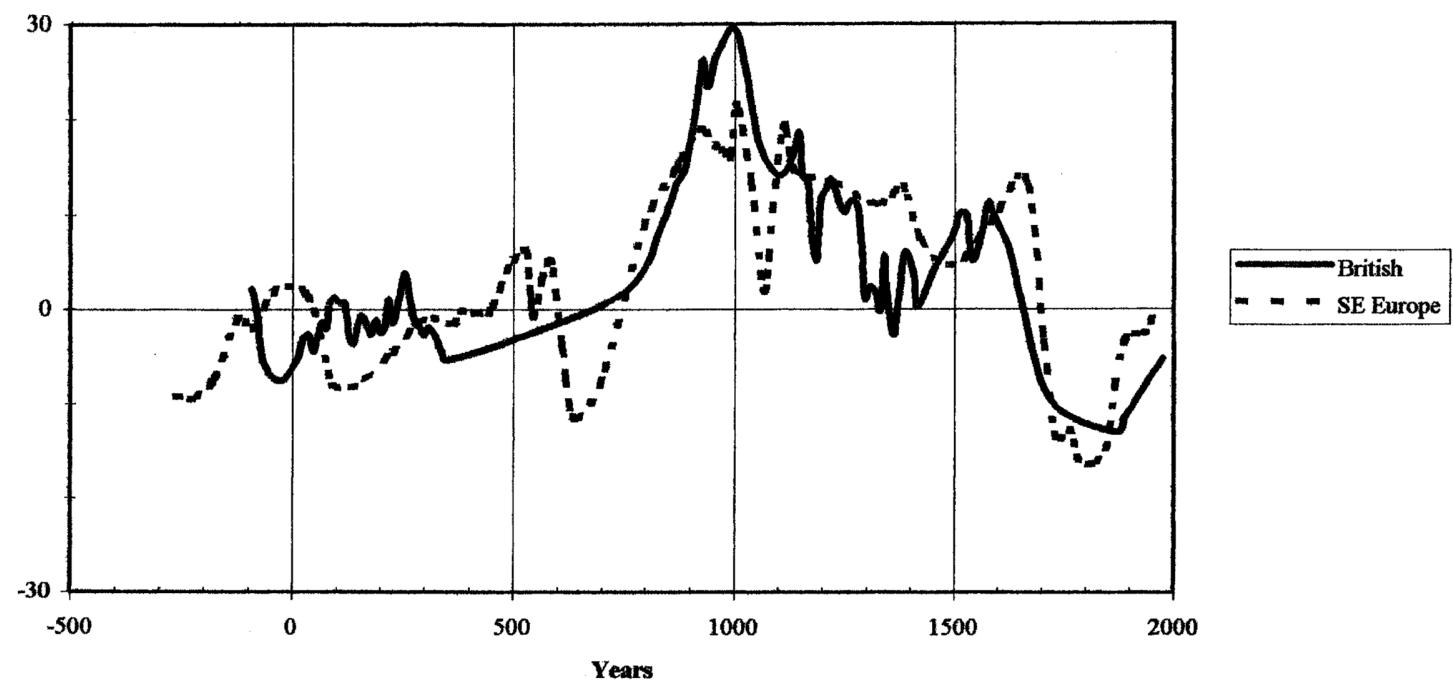

(a)

\section{Inclinations}

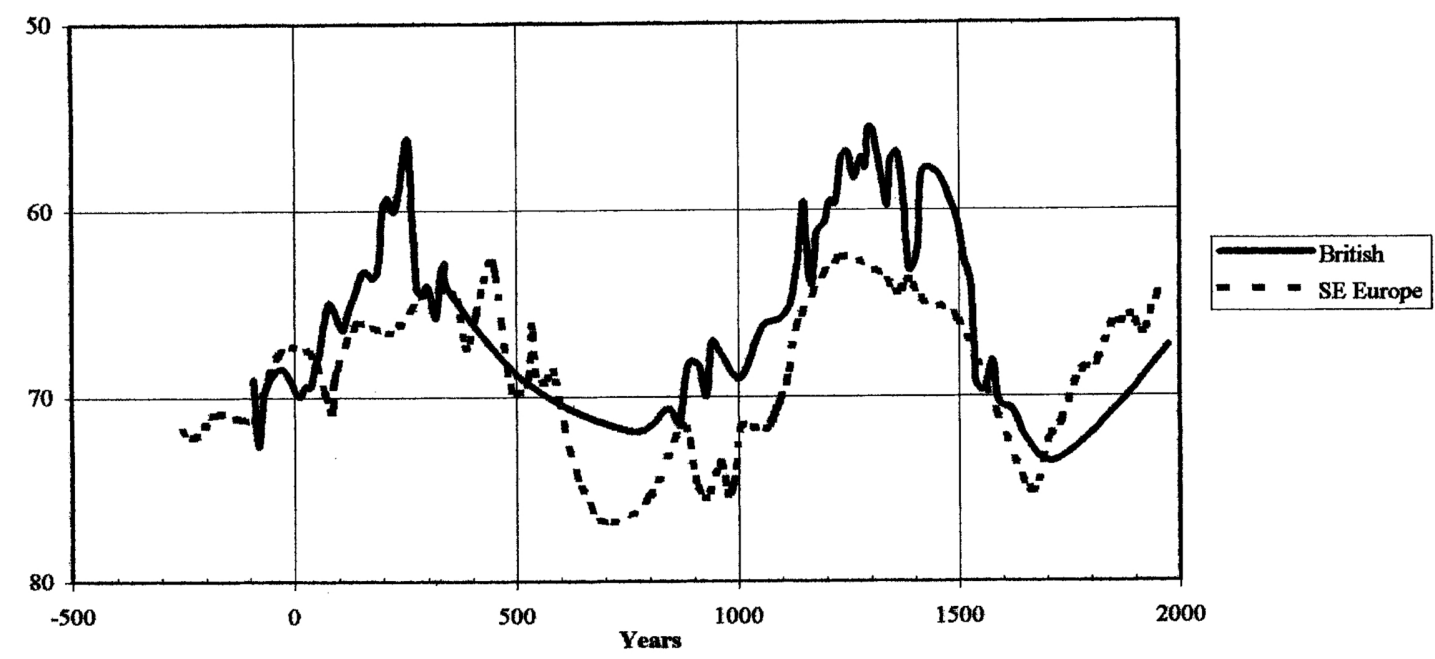

(b)

Fig. 3. The general trends for declination and inclination for both areas. The left hand diagrams are the trend lines associated with the decadal values, while those on the right are based on a two-point running mean. The dashed line is that for S. E. Europe after adding $7.16^{\circ}$ for the difference in latitude of the two locations on the basis of an axial geocentric dipole model for the total data sets (see text). 
was not reached in Britain until the early 13th century. The last maximum inclination was in the early 16 th century in S. E. Europe, but towards the end of the 16th century in Britain. Conversely for earlier times, the shallowest inclinations seem to have occurred in Britain earlier than in S. E. Europe, i.e. the early 3 rd century $\mathrm{AD}$ compared with the early 4th century $\mathrm{AD}$. There is thus some evidence for both westward and eastward drift of the secular variation of inclination during the last 2,000 years, but most differences could still lie within the unquantified errors in both databases, i.e. non-Gaussian age and archaeomagnetic errors outlines by Tarling and Dobson (1995).

The declination patterns for both areas, being more complex, are more difficult to evaluate. Taking the declinations since the 7th century, the increase in easterly declinations appears to be synchronous in both areas, as does the initial change back towards the west, but the rate of motion towards the west decreased in S. E. Europe in the mid 12th century, while the British declinations gradually changed towards the meridian in the mid 14th century, and then moved more easterly by 1600 , then moving westerly to reach a maximum westerly value in the late 19th century. The change to a more meridional value occurred slightly later in S. E. Europe, in the mid 16th century (after that in Britain) and the most easterly declinations around 1600 in Britain were also slightly before those in S. E. Europe. During the last 300 years, declination changes in S. E. Europe slightly preceded those in Britain. Any interpretation of the early declination pattern is hampered by the lack of British data. During Roman times, the change in declination appears to have at the same rate in both areas but the maximum westerly declination in Britain in the mid 1st century BC could be either lagging the S. E. European westerly declination in the third century $\mathrm{BC}$ or preceding the westerly declination in S. E. Europe in the second century AD.

A common assumption in palaeomagnetic studies is that the local secular variation pattern, over some few thousand years, averages out to that of the axial geocentric dipole field. It is of interest to compare this assumption with the limited archaeomagnetic data available from these two regions (Table 1). In both cases, the declinations do not quite average out to the axial geocentric dipole direction. Both mean declination values being more easterly, at a $95 \%$ probability level-the British data being the furthest away. This easterly bias reflects the easterly declinations that predominate from post Roman times, while the Roman declination remains close to the local meridian in both localities. The difference between the two mean declinations is almost entirely due to the easterly declinations recorded in the early 6th century

Table 1. The statistical parameters for the British and S. E. European regions. "Location" is the latitude, longitude of the reference location; "AGDF Decl., Incl." are the declination and inclination of the axial geocentric dipole field at the reference location. The Fisherian statistics are calculated giving unit weight to each decadal value, with $N$ the number of decadal values used, $R$ the resultant vector, with precision estimate $k$ and radius of $95 \%$ confidence, $\alpha_{95}$, (Fisher, 1953) and the c.s.d. as the circular standard deviation. Arithmetic values, with their corresponding ranges and standard deviations (s.d.), are based on using all terms as scalar values.

\begin{tabular}{|c|c|c|c|c|}
\hline \multirow[b]{2}{*}{ Location } & \multicolumn{2}{|c|}{ British } & \multicolumn{2}{|c|}{ S. E. European } \\
\hline & $52.43^{\circ}$ & $-1.62^{\circ}$ & $43.0^{\circ}$ & $25.0^{\circ}$ \\
\hline AGDF Decl., Incl. & $0.0^{\circ}$ & $68.96^{\circ}$ & $0.0^{\circ}$ & $61.80^{\circ}$ \\
\hline \multicolumn{5}{|l|}{ Fisherian } \\
\hline Decl., Incl. & $4.3^{\circ}$ & $64.4^{\circ}$ & $1.9^{\circ}$ & $62.3^{\circ}$ \\
\hline$N, R$ & 88 & 87.476227 & 58 & 57.623207 \\
\hline$k, \alpha_{95}$, c.s.d. & $1661.2^{\circ}$ & $6.3^{\circ}$ & $151 \quad 1.5^{\circ}$ & $6.6^{\circ}$ \\
\hline \multicolumn{5}{|l|}{ Arithmetic } \\
\hline Decl., Incl. & $4.2^{\circ}$ & $64.1^{\circ}$ & $2.1^{\circ}$ & $61.9^{\circ}$ \\
\hline Median Decl., Incl. & $1.7^{\circ}$ & $63.8^{\circ}$ & $0.1^{\circ}$ & $61.7^{\circ}$ \\
\hline Range Decl. & $34.3^{\circ}$ & $-18.2^{\circ}$ & $24.9^{\circ}$ & $-17.4^{\circ}$ \\
\hline Range Incl. & $74.4^{\circ}$ & $53.1^{\circ}$ & $71.9^{\circ}$ & $52.7^{\circ}$ \\
\hline s.d. Decl., Incl. & $\pm 9.1^{\circ}$ & $\pm 5.0^{\circ}$ & $\pm 11.1^{\circ}$ & $\pm 4.2^{\circ}$ \\
\hline
\end{tabular}


in S. E. Europe for which time there are, as yet, no records from Britain (Figs. 1 and 2). The mean inclinations are significantly shallower than the axial geocentric dipole field in Britain, but coincident with it, at a 95\% confidence level, for S. E. Europe. However, this discrepancy between the average inclinations could arise from the steeper inclinations recorded in S. E. Europe during the 6th and 7th centuries, for which time there are no records from Britain. In both areas, no individual sites actually record actual the axial geocentric dipole field direction (Tarling, 1988, 1989), suggesting the geomagnetic field may avoid this specific direction even though it may be centred on it over time scales of several thousand years.

\section{Conclusions}

Archaeomagnetic directional data are now becoming sufficiently abundant that it is possible to examine relatively small features of the secular variation patterns, isolating features that appear to be more stationary than others, and to assess the relative drift rates for non-stationary features. However, it must be emphasised that the current stated precisions commonly underestimate the actual errors in the technique (Tarling and Dobson, 1995) and that small differences, i.e. in the range of 2 to $3^{\circ}$, remain poorly defined and that there are still significant gaps in the available record for Western Europe. There is clearly a major need for the establishment of the direction of the geomagnetic field in Britain during the 4th to 7 th centuries AD. Nonetheless, there is evidence for cyclicity in some of the features of the geomagnetic field directional behaviour in both locations, although these remain too short to enable adequate definition. The clearest cyclicity is in inclination, consistent with a dominant intermediate wavelength of the order of 800 to 1000 years in both regions. The declination patterns are more complex, suggesting possible combinations of shorter wavelengths. Longer wavelengths are clearly present in both declination and inclination, but the extension of the time-base into the Bronze Age remains hampered by the imprecision of dating for older periods.

We would particularly like to acknowledge the help provide by Peter Marton, who pioneered archaeomagnetic studies in Hungary, and the two reviewers for their helpful comments. Copies of the Plymouth Archaeomagnetic Directional Database are available in ACCESS 2.0 from D. H. Tarling on the supply of an IBM formatted $\geq 1 \mathrm{Mb}$ floppy disk.

\section{REFERENCES}

Aitken, M. J., Dating by archaeomagnetic and thermoluminescent methods, Phil. Trans. $R$. Soc., Lond., A269, 77-88, 1970.

Aitken, M. J., H. N. Hawley, and G. H. Weaver, Magnetic dating: Further archaeomagnetic measurements in Britain, Archaeometry, 6, 76-80, 1963.

Batt, C. M., Archaeomagnetic dating: Investigating new materials and techniques, Ph.D. Thesis, Univ. Durham, 1992.

Chevallier, R., L'aimantation des laves de l'Etna et l'orientaton du champ terrestre en Sicile du XII au XVII siècle, Ann. Phys., 4, 5-162, 1925.

Clark, A. J., D. H. Tarling, and M. J. Noel, Developments in archaeomagnetic dating in Britain, J. Archaeo. Sci., 15, 645-667, 1988.

Fisher, R. A., Dispersion on a sphere, Proc. R. Soc., A217, 295-305, 1953.

Hartmann, G., Letter (published in Sz. Ges. Endkunde, 32, 112-136, 1897), 1544.

Hoye, G. S., Archaeomagnetic secular variation record of Mount Vesuvius, Nature, 291, 216-217, 1981.

Incoronato, A., Magnetic stratigraphy procedures in volcanic areas: The experience at Vesuvius, in Palaeomagnetism of the Mediterranean Region, edited by A. Morris and D. H. Tarling, pp. 367-371, Special Publ. Geol. Soc. Lond., 1996.

Iorio, M., D. H. Tarling, B. D'Argenio, G. Nardi, and A. E. Hailwood, Milankovitch cyclicity of magnetic directions in Cretaceous shallow-water carbonate rocks, Southern Italy, Boll. Geof. Teor. Appl., 37, 109-118, 1995.

Irving, E., Palaeomagnetism and Its Applications to Geological and Geophysical Problems, 399 pp., Wiley, New York, 1964.

Kato, Y. and T. Nagata, On the secular variation in geomagnetic declination in the Historic time of Japan, Proc. 7 th Pacific Sci. Congress, 2, 562-564, 1949.

Kovacheva, M., Inclination of the Earth's magnetic field during the last 2000 years in Bulgaria, J. Geomag. Geoelectr., 21, 563578, 1969.

Kovacheva, M., Updated archaeomagnetic results from Bulgaria: the last 2000 years, Phys. Earth Planet. Int., 70, $219-223,1992$. 
Kovacheva, M. and A. Toshkov, A. geomagnetic field variations as determined from Bulgarian archaeomagnetic data. Part 1. The last 2000 years AD, Surveys in Geophys., 15, 673-701, 1994.

Malin, S. R. C. and E. C. Bullard, The direction of the earth's magnetic field at London, 1570-1975, Phil. Trans. Roy. Soc., A299, 357-423, 1981.

Marton, P., Archaeomagnetic directional results from Hungary, Geophys. J. R. astr. Soc., 86, 719-725, 1986.

Marton, P., Archaeomagnetic directional data from Hungary: Some new results, in Archaeometry ' 90 , edited by E. Pernicka and G. Wagner, pp. 569-576, Birkhauser Verlag, Basel, 1991.

Nöel, M. and C. M. Batt, A method for correcting geographically separated remanence directions for the purpose of archaeomagnetic dating, Geophys. J. Int., 102, 753-756, 1990.

Shuey, R. T., E. R. Cole, and M. J. Mikulich, Geographic correction of archaeomagnetic data, J. Geomag. Geoelectr., 22, 485489, 1970.

Tarling, D. H., Palaeomagnetism, 379 pp., Chapman \& Hall, London, 1983.

Tarling, D. H., Secular variations of the geomagnetic field-the archaeomagnetic record, in Secular Solar and Geomagnetic Variations in the last 10,000 Years, edited by F. R. Stephenson and A. W. Wolfendale, pp. 349-365, Kluwer Acad. Publ., Dordrecht, 1988.

Tarling, D. H., Geomagnetic secular variation in Britain during the last 2000 years, in Geomagnetism and Palaeomagnetism, edited by F. J. Lowes, D. W. Collinson, J. H. Parry, S. K. Runcorn, D. C. Tozer, and A. Soward, pp. 55-62, Kluwer Acad. Publ., Dordrecht, 1989.

Tarling, D. H. and M. J. Dobson, Archaeomagnetism: An error assessment of fired material observations in the British Directional Database, J. Geomag. Geoelectr., 47, 5-18, 1995.

Thellier, E., Magnetisme Interne, in Encyclopedie de la Pleiade, pp. 235-376, 1966.

Thellier, E., Sur la direction du champ magnétique terrestre, en France, durant le deux derniers millénaires, Phys. Earth Planet. Int., 24, 89-132, 1981.

Thompson, R., A comparison of geomagnetic secular variation as recorded by historical, archaeomagnetic and palaeomagnetic measurements, Phil. Trans. Roy. Soc. Lond., A306, 103-112, 1982.

Turner, P., Palaeozoic secular variation recorded in Pendleside Limestone, Nature, 257, 207-208, 1975. 